\title{
Bitter Melon Seed Extract does not Alter Photoperiodic Effects on Reproduction of Male Golden Hamsters
}

\author{
Donchan Choi, Su Ji Lee, Min Hyuck Lee and Dong Kyu Lee \\ Department of Life Science, College of Environmental Sciences, Yong-In University, Yongin 17092, Korea
}

\begin{abstract}
Bitter melon (Momordica charantia, MC) has been used in traditional Korean medicine in treating diabetes. In addition, some reports were emerged, showing the antifertility activities of MC in mammals. We investigated the effects of ethanolic MC extract on the reproductive activity of golden hamsters whose spermatogenetic capacity is controlled by their photoperiods. The animals were divided into 4 groups: long photoperiod (LP) control, short photoperiod (SP) control, and LP animals treated with MC. The animals were orally ingested with low $(0.03 \mathrm{~g} / \mathrm{kg})$ or high $(0.15 \mathrm{~g} / \mathrm{kg})$ concentrations of the ethanolic extracts for 8 weeks on the daily basis. The control animals received the vehicle. The animals were then mated with age-matched females, experienced pregnancy. As results, the LP control animals showed active large testes but SP control animals displayed remarkably reduced testes. The animals treated with both concentrations of MC extracts demonstrated large testes, indicating fertile activity as animals in LP. LP control animals had litters as expected, but SP controls had no litters at all. MC extract showed the same results as LP animals in generating offsprings. These results suggest that the MC extract does not change the photoperiodic influence on reproductive activity of male golden hamsters.
\end{abstract}

Key words : Momordica charantia, Photoperiod, Reproductive activity, Golden hamster

\section{INTRODUCTION}

Reproductive capacity of small mammals living in temperate region displays unique characteristics from species to species. Almost all the animals do not possess the reproductive function throughout the entire year (Choi \& Han, 2010; Choi \& Lee, 2012). This is a revolutionary consequence because a large amount of energy is required in maintaining the energetic sexual activity. Thus most of animals reproduce for a particular period of time in a year, sparing the energy and keeping the species unimpaired.

There are a number of reports, indicating that reproductive activities of mammals are altered by herbal extracts
(Abdel-Rahman, et al., 1999; Tajuddin et al., 2004; Mishra \& Singh, 2008; Yang et al., 2010; Lee, et al., 2013; Choi, et al., 2014). The bitter melon (Momordica charantia) is a tropical and subtropical vine of the family Cucurbitaceae, which is originated in India. it is grown in Asia, Africa, and the Caribbean regions, including Korea. The different parts of the plant have been used as a culinary materials of various foods in many countries. Also as herbal medicine, its extracts have been well-known for a hypoglycemic effect (Lo et al., 2013). Bitter melon reduces adiposity, lowers serum insulin, and normalizes glucose tolerance in rats fed a high fat diet (Chen et al., 2003). In addition, a variety of ailments are subjected to treat stomach, laxative,

\footnotetext{
Manuscript received June 5, 2017, Received in revised form June 8, 2017, Accepted June 12, 2017

${ }^{\dagger}$ Corresponding Author : Donchan Choi, Dept. Life Science, College of Environmental Sciences, Yong-In University, Yongin 17092, Korea, Tel: +82-318020-2781, Fax: +82-31-8020-2886, E-mail: dcchoi@yongin.ac.kr

This is an Open Access article distributed under the terms of the Creative Commons Attribution Non-Commercial License (http:// creativecommons.org/licenses/by-nc/3.0) which permits unrestricted non-commercial use, distribution, and reproduction in any medium, provided the original work is properly cited.
} 
antibilious, emetic, anthelmintic agent, cancer, and infections (Wang et al., 2017). Some side effects are reported for diarrhea, abdominal pain, fever, and chest pain. But the symptoms are mild, requiring no further treatment.

Lately, there were some reports that the extract of the MC seeds caused infertility in male rat (Girini et al., 2005; Tumkiratiwong et al., 2014). In the examination of morphological changes in sperm of albino rats, the alcoholic extract of MC seed showed the disturbance in the plasma membrane as well as in the acrosomal membrane in scanning electron microscopy. The results indicate the antiandrogenic property of MC seeds (Girini et al., 2005). The antisteroidogenic activities as well as antisperma-to-genic effects was observed in male rat (Naseem et al., 1998).

The golden hamster is one of the seasonal breeders whose reproductive activities are active around summer season (Choi \& Lee, 2012). In the winter climate the reproductive functions are completely arrested. This seasonal breeding strategy is determined by photoperiod that is the length of lighting in a day, which is surmised that the animal can predict possibly the annual cycle in a period of a year.

The fluctuating changes of seasonal reproductive function in the hamsters can be reproduced in the artificial lighting regime. When the reproductively mature male hamsters are transferred to SP (equal to and less than 12 hours of lights in a day), they lose generative activities, showing no functional spermatozoa in testes. If the length of lighting in a day is set to more than 12.5 hours (long photoperiod; LP) mimicking summer season, the generative functions are energetically resumed, doubtlessly promoted, and maintained afterward.

The goal of the present work was to investigate the effects of the MC extracts on the spermatogenesis in the testicular activity of male golden hamsters.

\section{MATERIALS AND METHODS}

\section{Plant material and extraction}

Seeds of Momordica charantia were purchased from the local traditional market in Korea. They were cultivated in designated area where the $\mathrm{MC}$ vine crept up the reticularformed net supported by pillars. The riped yellow fruits were gathered and the skin with pulp inside the fruit was discarded. The seeds were collected by removing the red arils surrounding them. They were fully dried in shadow and ground by Osterizer blender. Seventy percent of alcohol was used to immerse the powdered MC seeds for more than 60 days. The mixture was squeezed with woven texture to collect the fluid. The fluid was refined using coffee filters. Then it was dried in the oven kept at $60^{\circ} \mathrm{C}$. The solidified product was milled to make fine powder. The yield of the extract was $5.9 \% \mathrm{w} / \mathrm{w}$ in terms of dried starting material weights. One gram of powder of the extract was corresponded to 16.9 grams of dried seeds of MC. The powered extract was light brownish. The extract was preserved in a freezer and was dissolved with drinking water prior to usage.

\section{Animals}

Adult male golden hamsters (Mesocricatus auratus) weighing between 140-150 g were used for the study. They were housed in plastic cages under LP conditions of light and dark (light of $14 \mathrm{~h}$ : darkness of $10 \mathrm{~h}$ ) with an ambient temperature of $22 \pm 1{ }^{\circ} \mathrm{C}$. Reproductive activity of these hamsters are always active in the photoperiod. They were fed with standard laboratory mouse chow and tap water ad libitum. The condition of management of animals was approved by the Yongin University Institutional Ani-mal Care and Use Committee (YUIACUC-2015-04).

\section{Photoperiod treatment and intubation of the MC} extract

The golden hamsters were divided into four groups. The control animals were maintained in LP (light of $14 \mathrm{~h}$ : darkness of $10 \mathrm{~h}$ ) or SP (light of $10 \mathrm{~h}:$ darkness of $14 \mathrm{~h}$ ) 
and received the vehicle (drinking water). The experimental animals were housed in LP. The MC extract was dissolved in vehicle and was administered orally for 56 consecutive days using an intubation needle. The animals were received the MC extract at doses of $1.5 \mathrm{~g}$ (high dose) or $0.3 \mathrm{~g}$ (low dose) per $\mathrm{kg}$ of body weights on a daily basis. During this experimental period the body weights were measured every week. In 9th week, the animals were mated with age-matching females who had experienced pregnancy. They were cohabited with females for 8 days. Then the male animals were sacrificed. At the end of experiments testes were isolated and weighed to compare between groups. The internal organs were also dissected and weighed. During the period of time, the behaviour of animals was observed to examine any abnormal phenomenon due to long-term treatment.

\section{Fertility test}

Male hamsters were housed together with female hamsters who had experienced pregnancy in advance to evaluate the effect of MC extract on the fertility. The estrous cycle of female golden hamsters are exactly 96 hours, which is 4 days. Eight days were allowed to make sure the mating. Males were then removed and sacrificed for the parameters of this experiment. The fertility capacity was determined in 3 full weeks. The number of offspring from females who gave birth were recorded.

\section{Statistical analysis}

Data were expressed as mean \pm SEM. Statistical analysis was performed using Student's $t$-test. Differences were considered to be significant at $P<0.05$.

\section{RESULTS}

There was no any particular aberrant action in animals treated with the MC extract for 8 weeks. Thus, the MC extract was concluded not to induce any abnormal behavior.

The body weights of hamsters were measured at the regular intervals to evaluate any abnormal aspects in growth (Fig. 1). The body weights of animals in both LP and SP control gradually increased from the beginning of the experiment. The change of body weights during the entire experimental period of time was matched with the growth pattern. On the other hand, the body weights were inclined to diminish in two weeks of MC extract administration compared to the LP and SP control animals. The gaps were distinctly enlarged on the fifth week of MC extract administration, culminated with statistical difference $(P<0.05)$ on the sixth week, and later on slightly narrowed with similar significance at every week measured.

In order to examine any changes of internal organs, various organs were isolated and weighed at the end of the experiment (Table 1). Resultantly no weights of the organs were noticeably altered by the MC extract administration except for the reproductive-related organs, seminal vesicles and the epididymis. They were statistically $(P<0.05)$ reduced in only SP animals.

At the end of experiment the real weights of testes were in fact individually weighed. The changes of testicular weights are shown in Fig. 2. The mass of the testes was main tained in LP animals at the end of experiment but

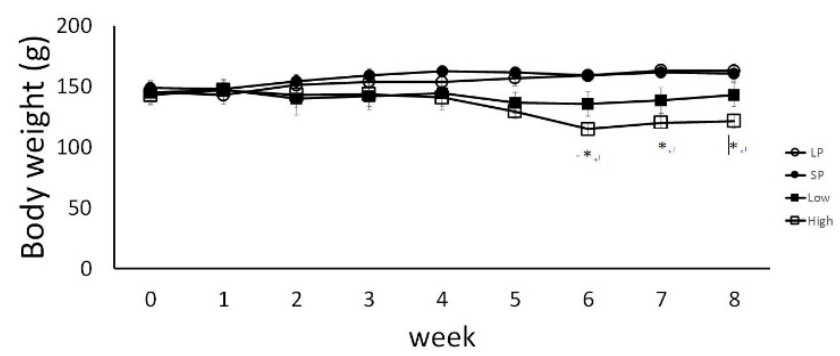

Fig. 1. The body weights of golden hamsters measured at one week intervals. LP: animals housed in LP and treated with vehicle, SP: animals housed in SP and treated with vehicle. Low and High: animals administered with low and high concentrations of the MC extract, respectively. Data are represented as the mean \pm SEM ( $\mathrm{n} \geqq 3)$. 
Table 1. Changes of weights of various organs

\begin{tabular}{ccccc}
\hline \hline & LP & SP & Low & High \\
\hline Heart (g) & $0.77 \pm 0.045$ & $0.83 \pm 0.036$ & $0.73 \pm 0.063$ & $0.94 \pm 0.157$ \\
Lung (g) & $1.09 \pm 0.100$ & $1.16 \pm 0.086$ & $0.84 \pm 0.086$ & $0.81 \pm 0.133$ \\
Liver (g) & $4.84 \pm 0.338$ & $5.51 \pm 0.356$ & $4.37 \pm 0.370$ & $3.89 \pm 0.685$ \\
Spleen (g) & $0.18 \pm 0.012$ & $0.21 \pm 0.029$ & $0.11 \pm 0.015$ & $0.17 \pm 0.027$ \\
Kidney (g) & $1.37 \pm 0.028$ & $1.33 \pm 0.061$ & $1.16 \pm 0.050$ & $1.14 \pm 0.199$ \\
Seminal vesicle (g) & $0.82 \pm 0.036$ & $0.31 \pm 0.066^{*}$ & $0.88 \pm 0.054$ & $0.71 \pm 0.129$ \\
Epididymis (g) & $0.84 \pm 0.108$ & $0.13 \pm 0.009^{*}$ & $0.75 \pm 0.090$ & $0.74 \pm 0.130$ \\
\hline
\end{tabular}

LP: animals housed in LP and treated with vehicle, SP: animals housed in SP and treated with vehicle. Low and High: animals administered with low and high concentrations of the MC extract, respectively.

Data are represented as the mean $\pm \operatorname{SEM}(\mathrm{n} \geqq 3)$.

${ }^{*}$ Denotes statistically significant difference $(p<0.05)$.

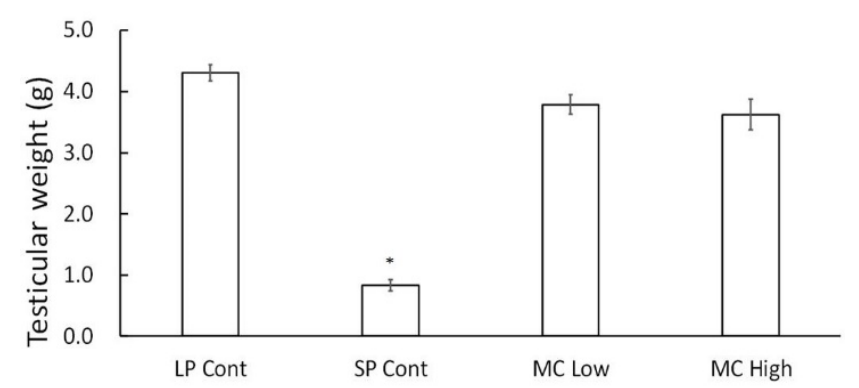

Fig. 2. Changes of testicular weights. Note that the only group of animals housed in SP showed statistical significance $(p<0.05)$ compared to all other groups at the end of experiment. LP: animals housed in LP and treated with vehicle, SP: animals housed in SP and treated with vehicle. Low and High: animals administered with low and high concentrations of the MC extract, respectively. * indicates statistical significance $(p<0.05) . \mathrm{n} \geqq 3$.

those in SP animals had statistically significant different $(P<0.05)$ testes when compared to the testes of the rest. Both the low and high concentration of MC treatments showed same large testes as in the LP control animals. The low and high concentrations of MC treatments showed large testes, which means ineffectiveness in blocking effects on testicular mass that is normally represented by SP.

Some male hamsters mated with female hamsters who previously gave birth to litters begot offsprings in every group except the animals in SP group. The groups in which gave delivery demonstrated about same pregnant ratio as animals in LP control. The ratio of males who had delivery was around $60 \%$, which is usual proportion of fertility fecundity in this golden hamsters. No statistically significant difference was observed in the weights of offsprings.

\section{DISCUSSION}

$\mathrm{MC}$ is a herbal plant which is usually recommended for treatment of many diseases, particularly diabetes. However, some studies showed that despite the diverse beneficial effects of MC (Bai et al, 2016; Czompa et al., 2017), it has a detrimental role on the reproductive system of male rats (Tumkiratiwong et al., 2014). The results of the present investigation showed no significant effects on the reproductive capability that is governed by photoperiods in male 
golden hamsters.

As well-established, golden hamsters kept in LP have constant large mass of testes that implies sexually active functional activity (Choi \& Han, 2010; Choi \& Lee, 2012). But the exposure to SP induces the regression of testes in the animals within the period of time of 8 weeks as described previously. Photoperiods are absolute regulator of the reproductive activity.

One of the methods to evaluate toxicity of plant extracts is to measure any unnatural changes in the body weight. In the present investigation no alterations in the body weights were observed in both LP and SP control groups. But golden hamsters treated with $\mathrm{MC}$ extracts showed significantly $(P<0.05)$ reduced body weights from the sixth weeks of the experiment, which is not the aim of the present examination. Nonetheless the extract of MC plant presents no general reproductive toxicity at the level of doses administered.

The present results showed that MC extract had the complete failure of blocking of fertilizing action of LP, which might be due to the possible shortage of the period of treatment time. But in other report, the authors reported reproductive toxicity effects in 6 weeks of treatment in rats (Tumkiratiwong et al., 2014). In case of golden hamsters, the period of 8 weeks has been reported to be enough to testify the sexual regression. With their results and the sufficient period of time of 8 weeks enough for induction of testicular regression in hamster species, the experimental period of time applied in this investigation is thought to elicit sexual involution. The possibility that longer administration could alter the photoperiodic effects on the sexual function in this animal is reasonably low.

Another point to be thought is a difference of animal species used in those experiments. The discrepancy could be due to the unique properties of animals, in which golden hamsters are seasonal breeders but rats are not. The extraction methods could be a factor induced the different results. The extraction method used in this experiment was nearly same as the previous reports in which the extraction agent was $70 \%$ ethanol (Tumkiratiwong, 2014). The concentration of the plant extract administered into the golden hamsters in this experiment was twice. The highest concentration administered into the animals here was $1.5 \mathrm{~g}$ per $\mathrm{kg}$ of body weight of animal, whereas Tumkiratiwong et al. used ethanolic seed extract at $0.8 \mathrm{~g}$ dry matter of per $\mathrm{kg}$ body weight. Nonetheless, they found a partial infertile results in rats. But in other aspect a point that might be worthy of notice is that there was still about $55 \%$ of the fertility testing.

Phytochemical studies indicate that the MC contains free eugenol, eugenol acetate, caryophyllene, sesquetrepene ester, phenyl propanoid, $\beta$ caryophyllene, acetyle eugenol (Adewale et al., 2014; Bai et al., 2016). However, the compounds had not been scientifically studied for their effect on sexual function. The earlier study using hydro alcoholic extract $(50 \%)$ of $\mathrm{MC}$ demonstrated the aphrodisiac activity (Tajuddin et al., 2004). Recently, the promoting effect of herbal extract on the reproduction was reported (Lee et al., 2013). But it needs further study for which ingredients have those effects and how they act within the body.

On the other hand, it is also not irrational that the ingredients of the MC extract would be converted into another substances by the metabolic process and work on the reproductive endocrine system. But it is not yet known which elements of the MC extract operate like those mentioned above. It could be greatly helpful to further examine the hormones in blood and the expression aspects of genes to uncover those action mechanisms.

The reproductive activities of golden hamsters is also controlled by gonadotropin releasing hormone ( $\mathrm{GnRH})$ as other mammals. And it has been well documented that the GnRH neurons in hypothalamus is indirectly affected by the melatonin, which is a major hormone secreted from the pineal gland (Choi, 2013). The synthesis and release of melatonin is proportional to the length of nighttime, thus melatonin is secreted for expanded period of time in winter, 
which is considered as an apparent involuting factor on reproductive activity in the golden hamsters.

For successful fertility, normal structure and accurate function of all parts of reproductive system are needed. A complex mechanism under the regulated function of the hypothalamic-pituitary-gonadal axis (HPG axis) is responsible for initiation and maintenance of spermatogenetic activity. Initially, GnRH in hypothalamus is produced and secreted to the pituitary that releases FSH and LH. FSH and LH acts on the testes. In the testes, LH stimulates the Leydig cells, located in interstitial tissue of seminiferous tubules. Then the cells produce and secrete testosterone. Simultaneously, FSH supports the function of sertoli cells, a mediator for effects of testosterone and exerts its effect on germ cells for successful spermatogenesis in seminiferous tubules.

The action mechanism of the MC extract could be speculated as follows no matter what animals were used. The $\mathrm{MC}$ extract is thought to act on the reproductive endocrine system by exerting its effect on GnRH neuronal cells. The MC extract swallowed by intubation into the animal body could be absorbed in the gastrointestinal tract and then spreaded all over the body through the circulatory system. Thus some compounds could act on hypothalamus, ultimately on the cells generating GnRH. Also in a similar manner, they may apply directly to the pituitary. But the evidence has not been assured.

Despite of the effect of SP on reproduction of the animals, the consequence of complete ineffectiveness by MC treatment could be related to the release of melatonin (Stetson \& Watson-Whitmyre, 1984; Stetson \& Watson-Whitmyre, 1986). That is, MC extract somewhat does not change the period of secretion of melatonin leading to involution, although the pattern of melatonin secretion was not examined. If that is the case, the $\mathrm{MC}$ extract is thought to nullify any modification of the gonadotropin releasing hormone $(\mathrm{GnRH})$ neuronal cells via melatonin to influence the release of FSH and LH from the anterior pituitary, which exert their effects on testicular function.

It is known that SP reduces the release of GnRH via the melatonin. Thus the MC extract possibly impinge on the action of melatonin, resulting in functional involution of reproductive activity in this animal. Moreover it can be speculated that they affect directly the testes as emphasized by the previous report (Tumkiratiwong et al., 2014). The components of the MC extract would operate on the Leydig cells to suppress the production of testosterone, and then the reduced amount of steroid influences the spermatogenesis. If it happened to golden hamsters, they should have had small regressed testes. In light of large testes that animals treated with MC (low and high dosages) displayed it is resonable that $\mathrm{MC}$ extract had no direct influences on testes. The outcome that MC extract was impotent on the reproductive activity of golden hamsters was evidenced by the offsprings who were born from the animals received the MC extract. Their pregnant ratio was similar to the LP controls, showing near $60 \%$ in generating offsprings. While SP control animals had no litters at all, implying complete degenerating effects of SP on testicular function.

In conclusion, the administration of MC extract did not alter the photoperiodic effects of LP on the reproduction of male golden hamsters. These results rule out the direct influence of $\mathrm{MC}$ on the testes, suspecting the antifertility action of MC presented in other animals. Thus MC extract could act on the reproductive activities via hypothalamopituitary gonad axis, including melatonin in the case of golden hamster. But it needs further study for how the natural product regulates the reproductive endocrine system within the body.

\section{REFERENCES}

Abdel-Rahman HA, El-Badry AA, Mahmoud OM, Harraz FA (1999) The effect of the aqueous extract of Cynomo-rium cocconieum on the epididymal sperm pattern of the rat. Phytother Res 13:248-250. 
Adewale OO, Oduyemi OI, Ayokunle O (2014) Oral administration of leaf extracts of Momordica charantia affects reproductive hormones of adult female Wistar rats. Asian Pac J Trop Biomed 4(Suppl 1):S521-524.

Bai LY, Chiu CF, Chu PC, Lin WY, Chiu SJ, Weng JR (2016) A triterpenoid from wild bitter gourd inhibits breast cancer cells. Sci Rep 6:22419-22428.

Bliss SP, Navratil AM, Xie J, Roberson MS (2010) GnRH signaling, the gonadotrope and endocrine control of fertility. Neuroendocrinology 31:322-340.

Chen Q, Chan LL, Li ET (2003) Bitter melon (Momordica charantia) reduces adiposity, lowers serum insulin and normalizes glucose tolerance in rats fed a high fat diet. J Nutr 133:1088-1093.

Choi D (2013) Potency of melatonin in living beings. Dev Reprod 17:149-177.

Choi D, Han E-H (2010) The impacts of photoperiods on hypothalamic proteins in the reproductive activities of golden hamsters. Dev Reprod 14:185-197.

Choi D, Lee S-H (2012) Neuroendocrine system in seasonal breeder: focusing on the reproductive activity of male golden hamster. Dev Reprod 16:1-8.

Choi D, Roh HS, Kang DW, Lee JS (2014) The potential regressive role of Syzygium aromaticum on the reproduction of male golden hamsters. Dev Reprod 18:5764.

Czompa A, Gyongyosi A, Szoke K, Bak I, Csepanyi E, Haines DD, Tosaki A, Lekli (2017) Effects of Momordica charantia (Bitter Melon) on ischemic diabetic myocardium. Molecules. 22:488-503.

Girini MM, Ahamed RN, Aladakatti RH (2005) Effect of graded doses of Momordica charantia seed extract on rat sperm: scanning electron microscope study. J Basic Clin Physiol Pharmacol 16: 53-66.

Lee JS, Oh HA, Kwon JY, Jeong MH, Lee JS, Kang DW, Choi D (2013) The effects of Cynomorium songaricum on the reproductive activity in male golden hamsters.
Dev Rep 17:37-43.

Lo HY, Ho TY, Lin C, Li CC, Hsiang CY (2013). Momordica charantia and its novel polypeptide regulate glucose homeostasis in mice via binding to insulin receptor. J Agric Food Chem 61:2461-2468.

Mishra RK, Singh SK (2008) Safety assessment of Syzygium aromaticum flower bud (clove) extract with respect to testicular function in mice. Food Chem Toxicol 46: 3333-3338.

Naseem MZ, Patil SR, Patil SR, Ravindra, Patil RSJ (1998) Antispermatogenic and androgenic activities of Momordica charantia (Karela) in albino rats. Ethnopharmacol 61: 9-16.

Stetson MH, Watson-Whitmyre M (1984) Physiology of the pineal and its hormone melatonin in annual reproduction in rodents. In "The pineal Gland" edited by Reiter R.J., Raven Press, New York, pp 109-153.

Stetson MH, Watson-Whitmyre M (1986) Effects of exogenous and endogenous melatonin on gonadal function in hamsters. J Neural Transm 21(Suppl):55-80.

Tajuddin, Ahmad S, Latif A, Qasmi IA (2004) Effect of 50\% ethanolic extract of Syzygium aromaticum (L.) Merr. \& Perry. (clove) on sexual behaviour of normal male rats. BMC Complement Altern Med 4:17-23.

Tumkiratiwong P, Ploypattarapinyo R, Pongchairerk U, Thong-Asa W (2014) Reproductive toxicity of Momordica charantia ethanol seed extracts in male rats. Iran J Reprod Med 12:695-704.

Wang S, Li Z, Yang G, Ho CT, Li S (2017) Momordica charantia: a popular health-promoting vegetable with multifunctionality. Food Funct 8:1749-1762.

Yang WM, Kim HY, Park SY, Kim H-M, Chang MS, Park SK (2010) Ethnopharmacological communication: $C y$ nomorium songaricum induces spermatogenesis with glial cell-derived neurotrophic factor (GDNF) enhancement in rat testes. J Ethnopharmacol 128:693-696. 